\title{
Immune response against HtrA proteases in children with cutaneous mastocytosis
}

\author{
Joanna Renke ${ }^{1 凶}$, Sabina Kędzierska-Mieszkowska1, Magdalena Lange2, \\ Bogusław Nedoszytko², Anna Liberek3 ${ }^{3}$ Katarzyna Plata-Nazar ${ }^{4}$, Marcin Renke ${ }^{5}$, \\ Tomasz Wenta', Dorota Żurawa-Janicka', Joanna Skórko-Glonek¹ and Barbara Lipińska'
}

1Department of General and Medical Biochemistry, University of Gdańsk, Gdańsk, Poland; ${ }^{2}$ Department of Dermatology, Venerology and Allergology Medical University of Gdańsk, Gdańsk, Poland; 'Faculty of Health Sciences with Subfaculty of Nursing, Medical University of Gdańsk, Gdańsk, Poland; ${ }^{4}$ Department of Pediatrics, Gastroenterology, Hepatology and Nutrition, Medical University of Gdańsk, Gdańsk, ${ }^{5}$ Department of Occupational, Metabolic and Internal Diseases, Medical University of Gdańsk, Gdynia, Poland

\begin{abstract}
Mast cells play an important role in both, the innate and adaptive immunity, however, clonal proliferation of abnormal mast cells in various organs leads to mastocytosis. A skin variant of the disease, cutaneous mastocytosis (CM) is the most frequent form of mastocytosis in children. HtrA proteases are modulators of important cellular processes, including cell signaling and apoptosis, and are related to development of several pathologies. The above and the observation that mast cells constitutively release the HtrA1 protein, prompted us to investigate a possible involvement of the HtrA proteins in pediatric $\mathrm{CM}$. Levels of the serum autoantibodies (IgG) against the recombinant HtrA proteins (HtrA1-4) in children with CM $(n=36)$ and in healthy controls $(n=62)$ were assayed. Anti-HtrA IgGs were detected using enzyme linked immunosorbent assay (ELISA) and Western-blotting. In the CM sera, levels of the anti-HtrA1 and anti-HtrA3 autoantibodies were significantly increased when compared to the control group, while the HtrA protein levels were comparable. No significant differences in the anti-HtrA2 IgG level were found; for the anti-HtrA4 IgGs lower levels in CM group were revealed. In healthy children, the IgG levels against the HtrA1, -3 and -4 increased significantly with the age of children; no significant changes were observed for the anti-HtrA2 IgG. Our results suggest involvement of the HtrA1 and HtrA3 proteins in pediatric $\mathrm{CM}$; involvement of the HtrA4 protein is possible but needs to be investigated further. In healthy children, the autoantibody levels against HtrA1, -3 and -4 , but not against HtrA2, increase with age.
\end{abstract}

Key words: HtrA proteases, children, cutaneous mastocytosis, mast cells

Received: 05 June, 2018; revised: 12 July, 2018; accepted: 16 July, 2018; available on-line: 27 August, 2018

e-mail: joanna.renke@biol.ug.edu.pl, jrenke@gumed.edu.pl Abbreviations: AMD, age-related maculopapular degeneration; CM, cutaneous mastocytosis; DCM, diffuse CM; EM, extracellular space/matrix; HtrA, high temperaturę requirement $A$; IAPs, inhibitor of apoptosis proteins; KIT, tyrosine protein kinase; MC, mast cell; MPCM, maculopapular CM; SCF, stem cell factor; TGF $\beta$, tumor growth factor beta; XIAP, X-linked IAP; PDZ, PSD95, lglg, ZO1 domain; RA, rheumatoid arthritis, $\mathrm{SpA}$, spondyloarthritis

\section{INTRODUCTION}

The HtrA (high temperature requirement A) family serine proteases are modulators of important cellular functions which are well conserved in evolution. Gener- al function of these proteases is to control quality of cellular proteins by degradation of aberrant proteins arising in a cell as the result of improper folding or action of stress-inducing agents. Apart from functioning as protein quality controllers, HtrAs degrade specific undamaged proteins and thus participate in regulation of many cellular processes. A characteristic feature of the HtrA family members is the presence of a chymotrypsin-like protease domain and at least one PDZ domain at the C-terminus; the $\mathrm{N}$-terminal region is variable and contains signal and regulatory motifs (Clausen et al., 2011; Hansen et al., 2013).

There are four human members of the HtrA family, HtrA1-4. They function under normal and stress conditions, and participate in regulation of apoptosis, cell signaling and motility, maintenance of mitochondrial homeostasis, bone formation, embryo implantation and other processes. Their loss or dysfunction contribute to development of severe pathologies, including oncogenesis, neurodegenerative diseases and arthritic disorders, thus they are considered as potential therapeutic targets (Chien et al., 2009; Skorko-Glonek et al., 2013) or prognostic markers (Zhao et al., 2016). Many as yet unidentified diseases may be linked to aberrations in the HtrA activity. Interestingly, it has been shown that HtrA1 is highly upregulated during in vitro differentiation of the murine mast cells (MCs) and that the human MCs release HtrA1 constitutively, independently of degranulation (Gilicze et al., 2007).

MCs play an important role in both, the innate and adaptive immunity, including response to bacterial, viral and parasitic pathogens, and immune tolerance. Conversely, their overproduction or hyperactivity may lead to mastocytosis or allergic diseases, respectively. Mast cell functions are related to their ability to produce and secrete a diverse array of inflammatory mediators. Mast cell activation can lead to release of preformed mediators, stored in the cytoplasmic granules; lipid mediators, derived from membrane lipids; and neosynthesized mediators, which are produced following transcriptional activation. Some mediators may be released constitutively (Da Silva et al., 2014).

Mastocytosis is a heterogeneous disease, characterized by proliferation of morphologically and immunophenotypically abnormal MCs in various organs, especially in the skin, where it is referred to as cutaneous mastocytosis (CM). CM has three major clinical manifestations - maculopapular CM (MPCM), diffuse cutaneous mastocytosis (DCM) and mastocytoma of the skin. CM, spe- 
Table 1. General characteristics of the CM patients and control groups.

Patients with $\mathrm{CM}^{1}(\mathrm{n}=36)$

Type of the disease

\begin{tabular}{lc}
\hline $\mathrm{MPCM}^{2}=34$ & $\mathrm{DCM}^{3}=2$ \\
\hline Gender & Girls $(n=17)$ \\
\hline Boys $(n=19)$ &
\end{tabular}

Age of patients (years)

Range 1-17 Median 2

Tryptase level* $(\mathrm{ng} / \mathrm{ml})$ Mean \pm S.D.

$13.46 \pm 21.41$

Control group $1(\mathrm{n}=28)$

Gender

Boys $(n=11)$

Girls $(n=17)$

Age of children (years)

Range 1-17 Median 10

Control group $2(\mathrm{n}=34)$

Subgroup $1(n=16)$

Subgroup $2(n=18)$

Age of children (years)

\begin{tabular}{cccc} 
Range & Median & Range & Median \\
\hline $1-8$ & 4 & $9-17$ & 9.16 \\
\hline
\end{tabular}

Gender

$\begin{array}{llll}\text { Boys } & \text { Girls } & \text { Boys } & \text { Girls } \\ n=7 & n=9 & n=11 & n=7\end{array}$

CM, cutaneous mastocytosis; MPCM, maculopapular type; DCM, diffused cutaneous mastocytosis. (*), Serum concentrations of tryptase were determined by using a fluoroimmunoenzymatic assay (FEIA) with a UniCAP Tryptase kit and UniCAP100 analyzer (Phadia, Uppsala Sweden), following instructions provided by the manufacturer.

cifically MPCM, is the most frequent form of mastocytosis in children (Lange et al., 2013). The clinical course of pediatric CM is different than in adult onset of CM. A spontaneous resolution of $\mathrm{CM}$ in children is frequent in mastocytoma and is expected for MPCM by the adolescence period (Heinze et al., 2017); these observations may suggest a different CM pathogenesis depending on the developmental age.

Abnormal growth and accumulation of clonal MCs in mastocytosis is related to the facts that the stem cell factor (SCF) and the SCF receptor KIT are critical for mast cell proliferation, differentiation, and survival, and that

\section{A}

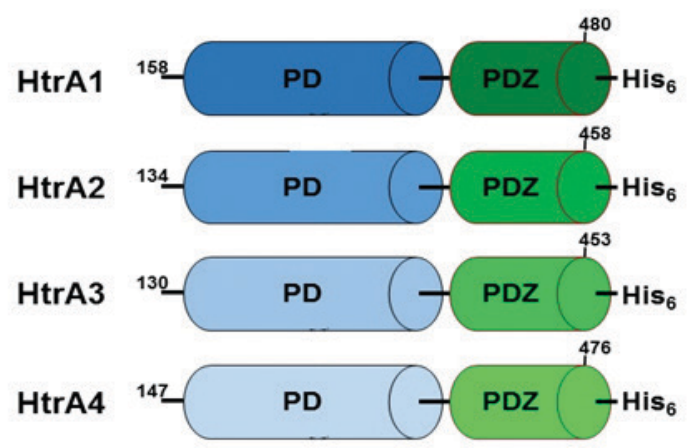

B

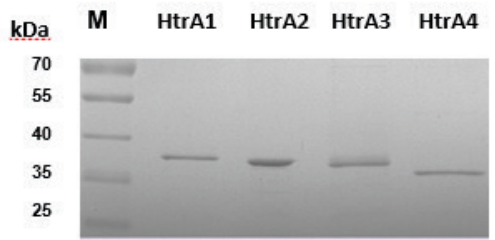

Figure 1. Presentation of the recombinant HtrA proteins used in this study.

(A) Domain organization of the HtrA proteases. Recombinant proteins were created without the $\mathrm{N}$-terminal domains and with the His6-tags at their C-terminal ends (calculated molecular mass 36 $\mathrm{kDa}$ for each protein). PD, chymotrypsin-like protease domain; PDZ, PDZ domain. Numbers indicate the $\mathrm{N}$ - and the C-terminal amino acid residues of the HtrA polypeptides. (B) Coomassie bluestained SDS-PAGE gel showing the purified HtrA proteins $(1 \mu \mathrm{g})$ used as antigens in ELISA assays and in Western blotting analyses. The positions of protein size markers (M) (in kDa), PageRuler Prestained Protein Ladder (Thermo Scientific), are shown on the left.

in majority of cases normal KIT function is disrupted by activating mutations. These mutations are associated with constitutive activation of the tyrosine kinase KIT and initiation of the pro-proliferative signals. However, inhibition of mast cell apoptosis through other biological pathways may also contribute to the pathogenesis of mastocytosis. In some patients, anti-apoptotic mutations or constitutive expression of the anti-apoptotic Bcl proteins have been found (Metcalfe \& Mecori 2017).

The well-established role of the HtrA proteins in apoptosis and cell signaling, as well as the fact that HtrA1 is released by MCs constitutively (Gilicze et al., 2007), prompted us to investigate a possible involvement of the HtrA proteins in pediatric CM. In this study, we evaluated the immune response to the HtrA1-4 proteins in children with $\mathrm{CM}$, in comparison to the healthy controls.

\section{MATERIALS AND METHODS}

Patients. The general characteristics of patients enrolled in this study are presented in Table 1.

The enrolled subjects were patients of (i) the Department of Dermatology, Venerology and Allergology, and of (ii) the Clinic for Immunological Diseases of Children at the Medical University of Gdansk, between the years of 2012 and 2015. Healthy children were undergoing routine diagnostic tests due to psychosomatic disorders, while potential other suspected illnesses were excluded. All sera had been stored at $-80{ }^{\circ} \mathrm{C}$ until analysis. The study protocol was approved by the Independent Bioethics Committee for Scientific Research at the Medical University of Gdansk, Poland, approval no. NKBBN/520/2014 and NKBBN/520-119/2016.

Preparation of recombinant antigens. The human HtrA recombinant proteases (HtrA1-4), without the N- 
terminal domains (i. e. $\Delta \mathrm{N}-\mathrm{H} \operatorname{tr} \mathrm{A}$ ) and with the hexa-histidine tags at their C-terminal ends (Fig. 1), were overproduced with a $\mathrm{pET}$ system (Novagen) and purified by Ni-NTA affinity chromatography as previously described elsewhere (Lipinska et al., 1990). The identity of the purified proteins was confirmed by Western blotting using a commercial antibody against the appropriate HtrA protein (Sigma, SAB1402047; ThermoFisher Scientific, PA1-41149) or a liquid chromatography-tandem mass spectrometry (LC-MS/MS) analysis of tryptic peptides obtained after trypsin cleavage of the protein, performed at the MS LAB IBB PAN (Warsaw, Poland). The equipment used was sponsored in part by the Centre for Preclinical Research and Technology (CePT), a project co-sponsored by the European Regional Development Fund and Innovative Economy, The National Cohesion Strategy of Poland.

Enzyme-linked immunosorbent assay (ELISA). ELISA assay was performed according to the standard protocols using $50-\mu \mathrm{l}$ volumes in all steps except for blocking, for which $100 \mu \mathrm{l}$ were used. Costar 96 well EIA/RIA polystyrene high-binding plates were coated with $50 \mu \mathrm{l}$ of $0.313 \mu \mathrm{g} / \mathrm{ml}$ of the appropriate recombinant HtrA protein (a capture antigen) in phosphate-buffered saline (PBS) by overnight incubation at $4^{\circ} \mathrm{C}$. The HtrA protein concentration was estimated by staining with Amido Black as described earlier (Lipinska et al., 1990). The plates were washed five times with

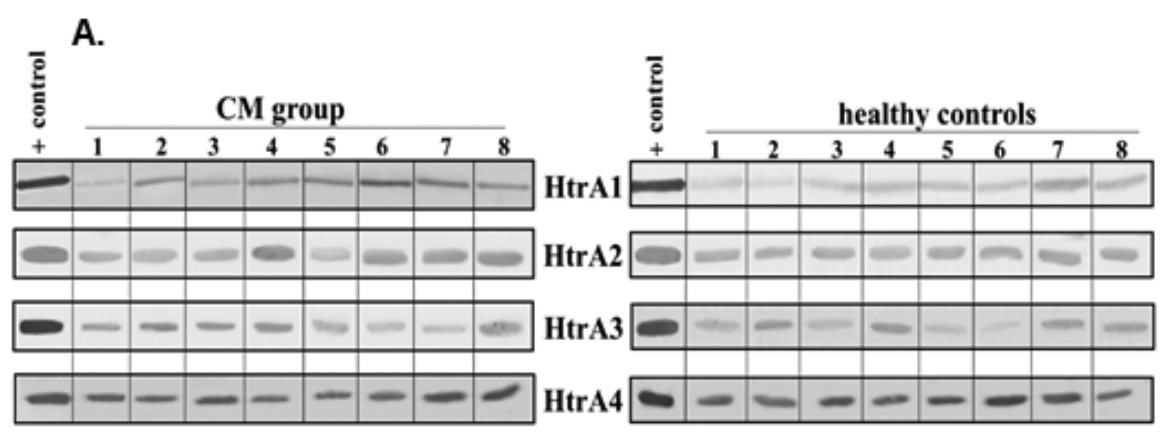

B. anti-HtrA1 antibodies

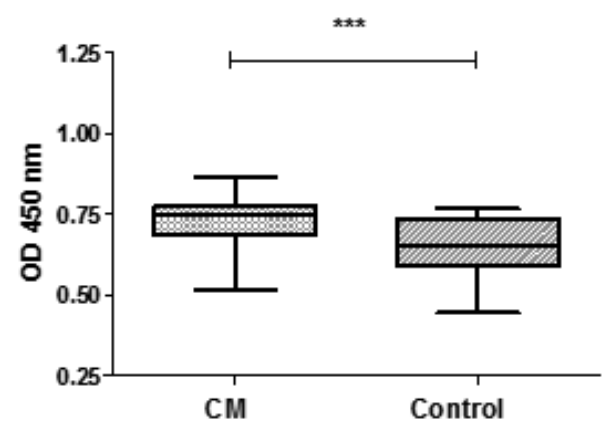

\section{D. anti-HtrA3 antibodies}

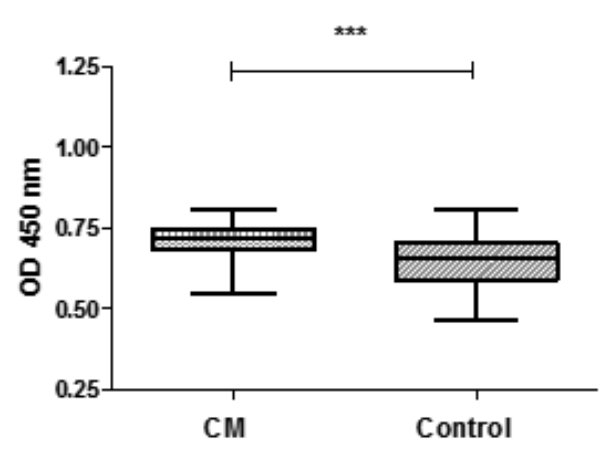

C. anti-HtrA2 antibodies

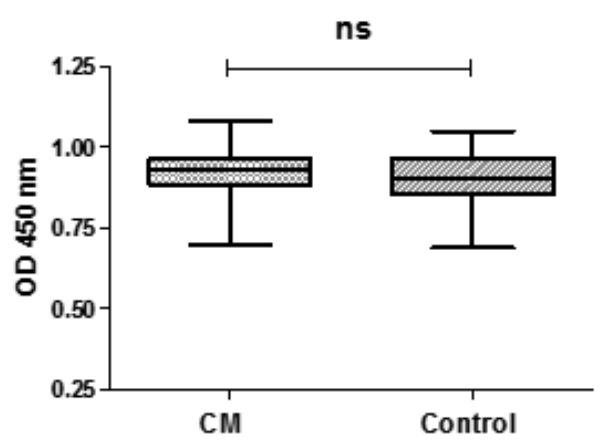

E. anti+HtrA4 antibodies

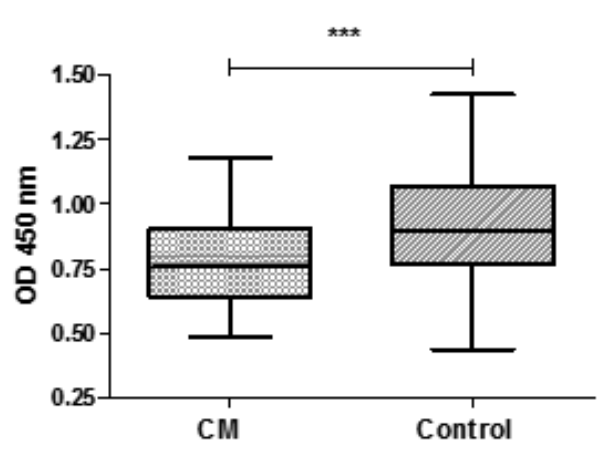

Figure 2. Comparison of the serum antibody levels against the HtrA proteins in children with $\mathrm{CM}$ and in healthy individuals.

(A) The purified HtrA proteins $(250 \mathrm{ng})$ were resolved by SDS-PAGE and Western blotting was performed, using the sera of the CM and healthy children (control group 1, Table 1) as the primary antibodies. The blots were developed using nitrotetrazolium blue chloride (NBT, Sigma) and 5-bromo-4-chloro-3-indolyl-phosphate disodium salt (BCIP, Sigma) as chromogens. The positive control (+control) lanes show immunoblotting with the appropriate anti-HtrA rabbit antibodies. Only representative immunoblots are shown. (B-E) Serum levels of the anti-HtrA1-4 IgGs were assayed by ELISA in children with CM $(n=36)$ and in healthy children as a control $(n=28$, control group 1, Table 1). All serum samples were analyzed in duplicate. The data were analyzed using the Mann Whitney $U$ test. Boxes represent the $25-75 \%$ range of the data, whiskers represent $\min$ and max, and horizontal lines represent the medians. $\left.{ }^{* * *}\right)$ denotes $p<0.0001 ; n s$, not statistically significant. CM, children with cutaneous mastocytosis; controls, healthy children. 
A
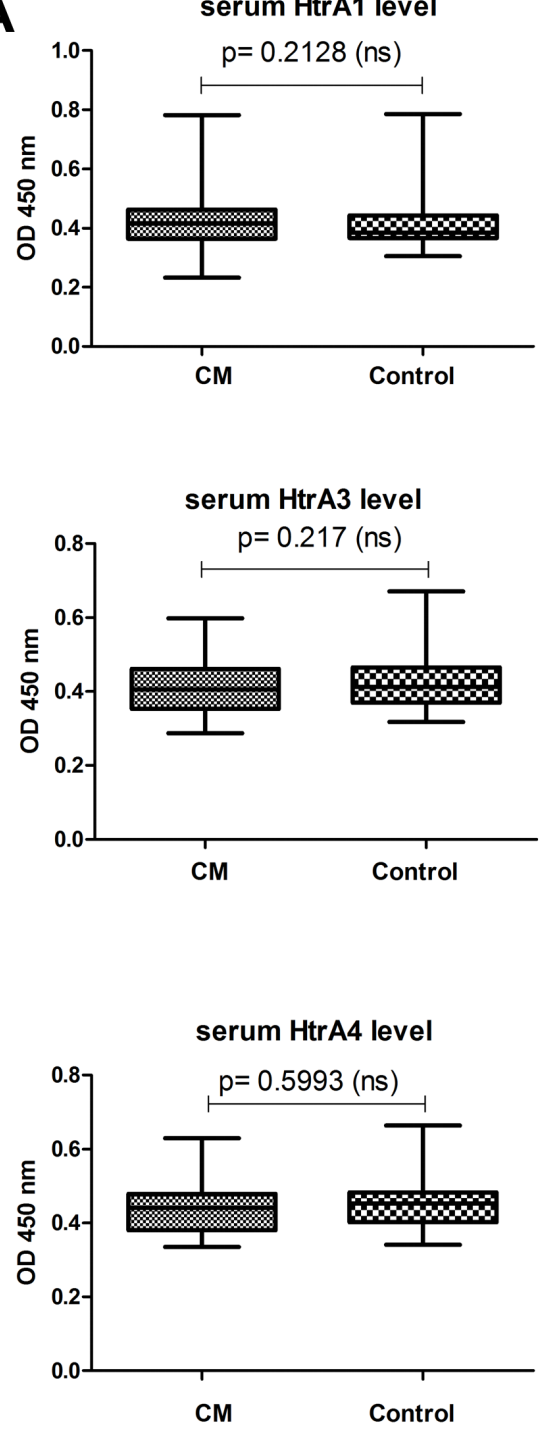
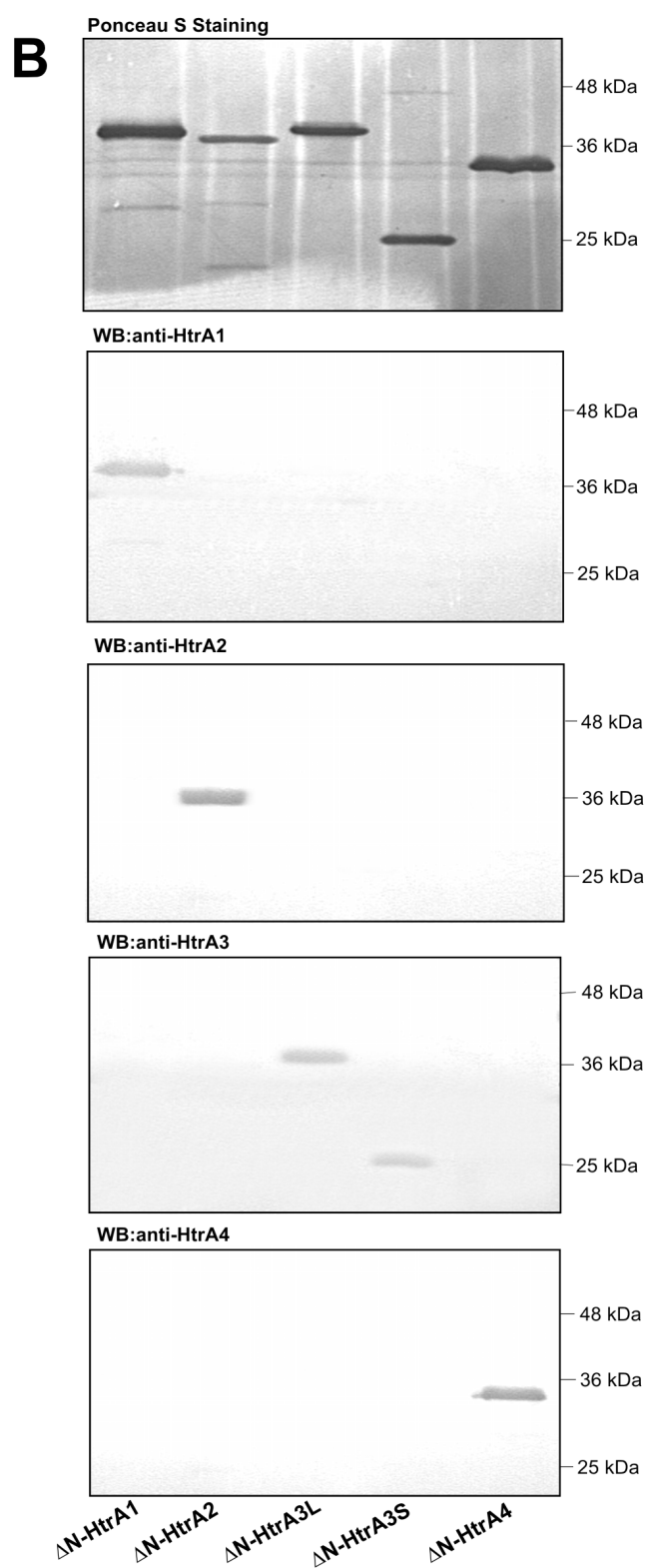

Figure 3. Serum levels of the HtrA proteins in children with CM and in healthy individuals.

(A) Serum levels of the HtrA proteins were assayed by ELISA in children with CM $(n=36)$ and in healthy children as a control $(n=28)$. All serum samples were analyzed in duplicate. The data were analyzed using the Mann Whitney $U$ test. Boxes represent the $25-75 \%$ range of the data, whiskers represent $\min$ and $\max$, and horizontal lines represent the medians. ns, not statistically significant. (B) The rabbit anti-HtrA antibodies used in the ELISA shown in A were tested for cross-reactivity by Western blotting, using the recombinant human HtrA proteins. Since HtrA3 has two isoforms, the long (L) an short (S) form, both were tested.

PBST buffer (PBS containing 0.05\% Tween 20) and the non-specific binding sites were blocked by incubation with $100 \mu \mathrm{l}$ of $0.1 \%$ Tween 20 in PBS buffer for $1 \mathrm{~h}$ at room temperature. The human serum samples were diluted 100-fold and an appropriate positive control serum at the optimal dilution (1:1000-1:2500) in PBST buffer were applied (in duplicate or quadruplicate) to the wells and incubated at $37^{\circ} \mathrm{C}$ for $1 \mathrm{~h}$, followed by five rinses with PBST buffer. Next, secondary HRP-conjugated goat anti-human IgG (Abcam) (diluted 1:7000) or goat anti-rabbit $\mathrm{IgG}$ (Abcam) (diluted 1:10000) were added to each well and incubated for $1 \mathrm{~h}$ at $37^{\circ} \mathrm{C}$. The plates were then washed five times with PBS buffer and 3,3',5,5'-tetramethylbenzidine (TMB) (Sigma) was added to detect the antibodies. The reaction was stopped after $10 \mathrm{~min}$ incubation at room temperature by the addition of $50 \mu \mathrm{l}$ of $1 \mathrm{M} \mathrm{H}_{2} \mathrm{SO}_{4}$. Absorbance at $450 \mathrm{~nm}$ was measured using PerkinElmer Multimode Plate Reader (Enspire). The assay was performed at least three times for each serum. For positive controls, rabbit polyclonal antibodies to the human HtrA1-4 proteins were used; they were raised as described earlier (Narkiewicz et al., 2008). When the level of the HtrA proteins in the sera was assayed, the ELISA test was performed in a similar way but the plates were coated with the human serum samples diluted 10-fold and then the rabbit antiHtrA1/3/4 sera diluted 2000 fold were added. The non-immune rabbit serum was used as a negative control and the purified recombinant HtrA proteins served as the positive controls.

SDS-PAGE and Western blotting analysis. To visualize binding of the human or rabbit anti-HtrA antibodies to a recombinant HtrA protein, SDS-PAGE elec- 
A. anti-HtrA1 antibodies

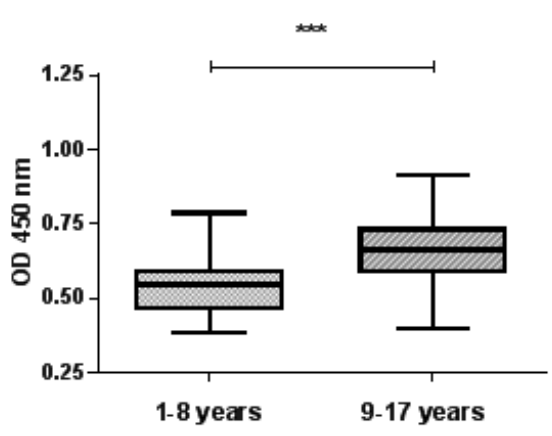

C. antiHtrA3 antibodies

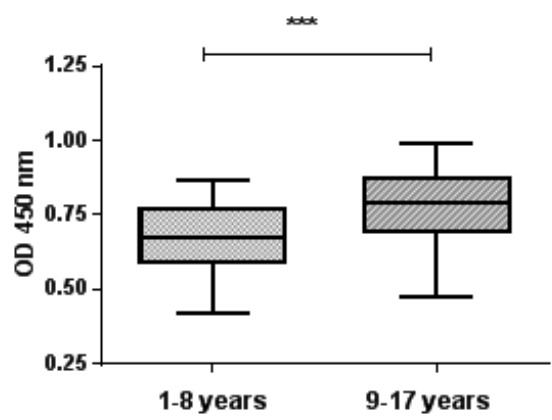

B. anti+HtrA2 antibodies

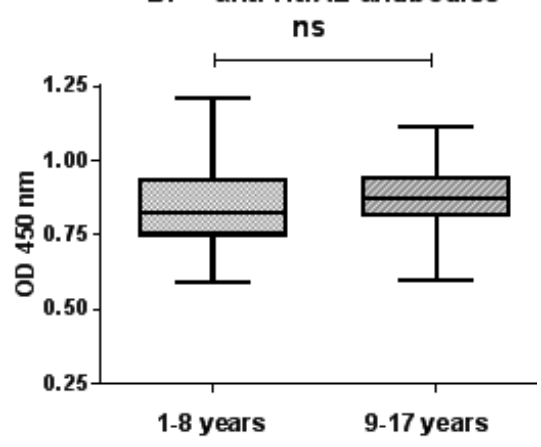

D. anti-HtrA4 antibodies

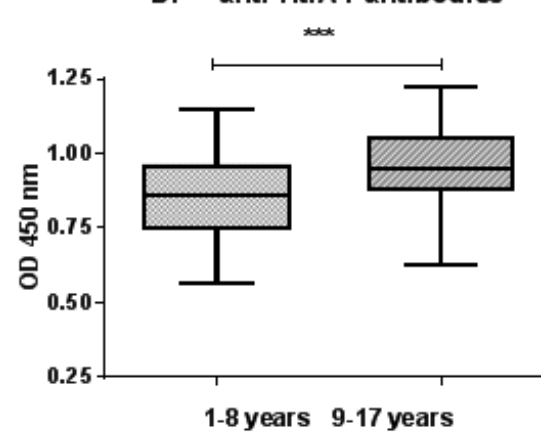

Figure 4. The levels of the anti-HtrA antibodies in the sera of children aged 1-17 years.

Serum levels of the anti-HtrA1-4 IgGs were assayed by ELISA in children aged 1-8 years $(n=16)$ and 9-17 years ( $n=18)$, (control group 1, Table 1). All serum samples were analyzed in quadruplicate. The data were analyzed using the Mann Whitney U test or the unpaired Student's $t$-test. Boxes represent the $25-75 \%$ range of the data, whiskers represent min and max, and horizontal lines represent the medians. $\left.{ }^{* * *}\right)$ denotes $p<0.0001 ; \mathrm{ns}$, not statistically significant.

trophoresis of the protein was performed according to (Laemmli et al., 1970) using $12.5 \%$ polyacrylamide gels; subsequently Western blotting was performed as described in (Harlow et al., 1988), using the anti-human $\mathrm{IgG}$ or anti-rabbit $\operatorname{IgG}$ antibodies.

Statistical analysis. The box-and-whisker graphs were performed using GraphPad Prism version 5.0 for Windows (GraphPad Software) and present the median values (the line in the middle of boxes) and the 25-75\% percentile (the box extension); the whiskers show min and max values. The Shapiro-Wilk test was used for assessing the normality of data distribution. The Mann Whitney U test or the unpaired Student's $t$-test was used to compare ELISA values between two subgroups. The Pearson test was used to analyze correlations between the anti-HtrA antibody levels and the patient's age. A two-tailed $p$ value $<0.05$ was considered as statistically significant.

\section{RESULTS}

To assess immune response against the human HtrA proteases in pediatric CM, we used the sera of children with CM $(n=36)$ and of the healthy controls $(n=28)$. Western blotting analysis showed that the tested sera contained varying levels of antibodies against each of the HtrA1-4 proteins (Fig. 2A). We then quantified the levels of the anti-HtrA antibodies by ELISA (Fig. 2B-E) and found that the CM sera contained significantly higher levels of the anti-HtrA1 and anti-HtrA3 IgG than the sera of healthy controls (panels B and D). Conversely, the anti HtrA4 IgG levels were significantly decreased in $\mathrm{CM}$ when compared to the control sera (Fig. 2E).
There were no significant differences in the anti-HtrA2 response (Fig. 2C). These results suggest involvement of the HtrA1, HtrA3 and HtrA4 proteins and/or the antibodies against them in CM. In spite of the differences in the anti-HtrA1/3/4 response between the $\mathrm{CM}$ and control children, the serum levels of the HtrA1//3/4 proteins in these groups were comparable, as revealed by ELISA test (Fig. 3A). The cross-reactivity of the rabbit anti-HtrA antibodies used in the ELISA test was not significant (Fig. 3B).

Since in the comparative study described above the median age of healthy children was higher than that of the CM patients, we undertook another study aimed at assessing changes in the anti-HtrA response due to the age of a patient. The ELISA test showed that in healthy children $(n=34)$, the serum levels of the anti-HtrA1, -HtrA3 and -HtrA4 IgGs were significantly lower in the group of younger children (1-8 years) than in the 9-17 years' group; no significant changes were observed for the anti-HtrA2 IgGs (Fig. 4). Statistically important correlations with age for the anti-HtrA antibodies were found - the IgG levels against the HtrA1, -3 and -4 proteins increased in parallel with the age of children, with the highest statistical significance in the case of the antiHtrA1 and -HtrA3 IgGs (Fig. 5, panels A and C).

\section{DISCUSSION}

The study presented here was aimed at investigating a possible relation between the pediatric $\mathrm{CM}$ and the HtrA1-4 proteins. This relation was suggested by the facts that HtrA1 had been shown to be constitutively released by the MCs (Gilicze et al., 2007) and that the 

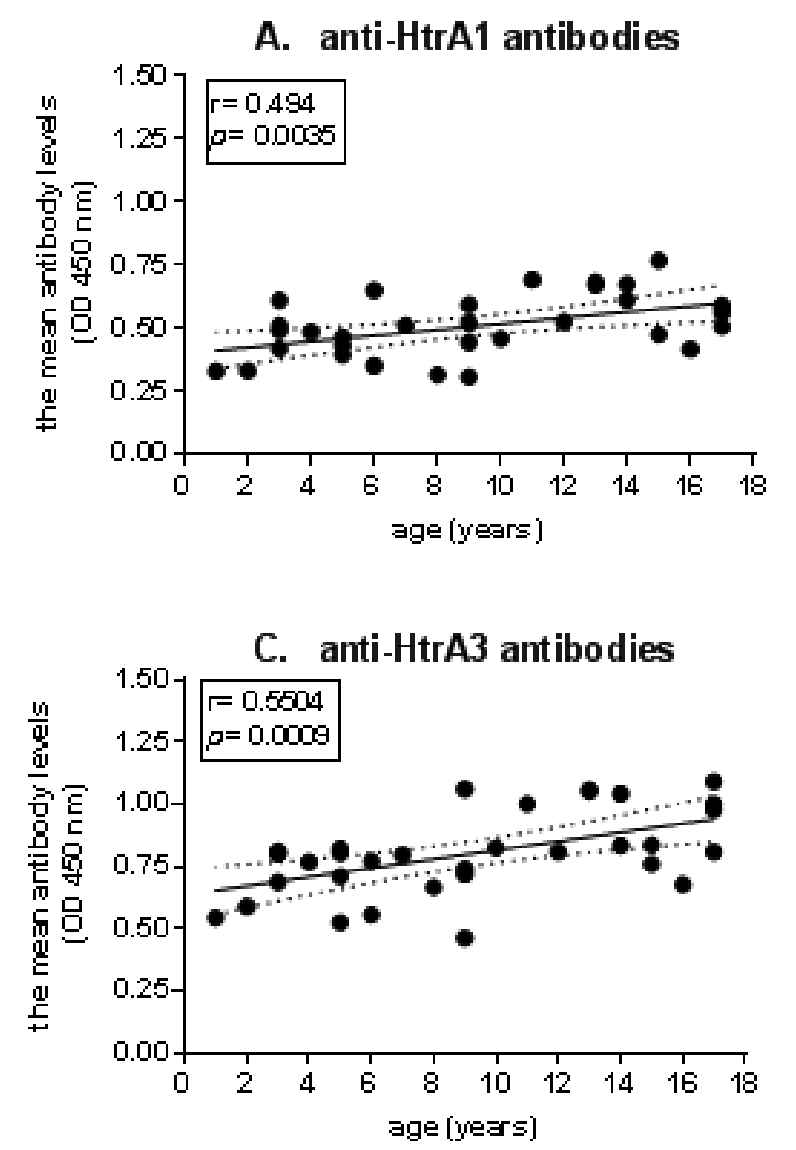

B. anti-HtrA2 antibodies
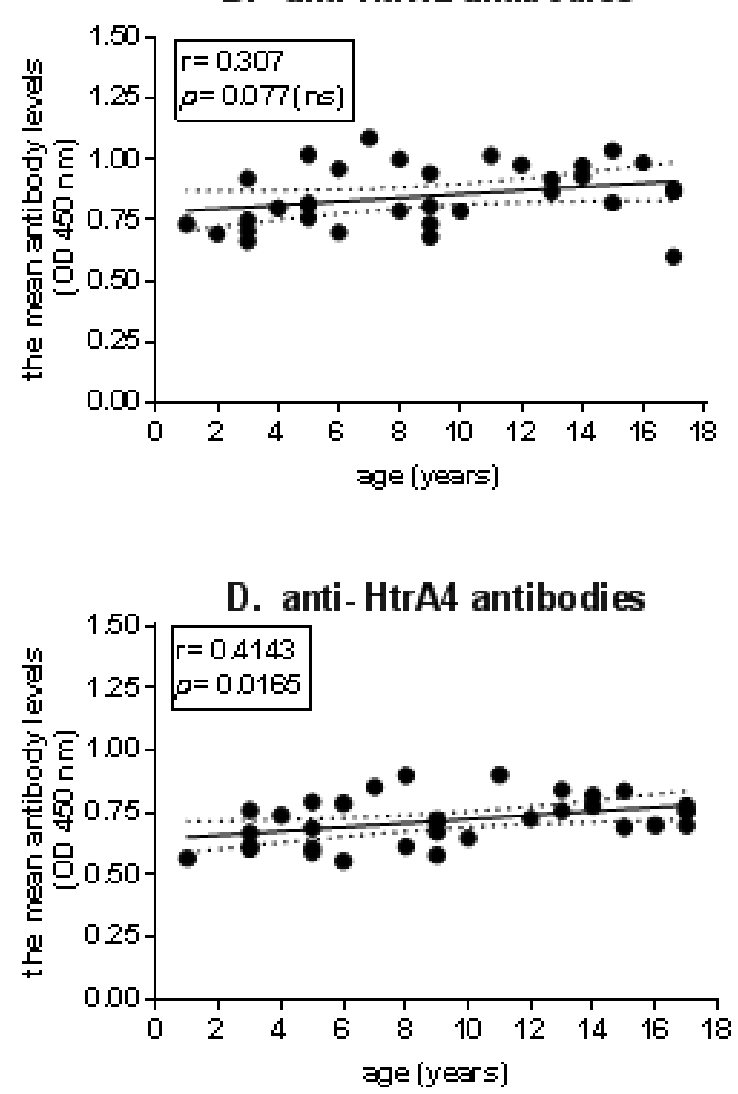

Figure 5. Correlations between the serum antibody levels against the HtrA proteins and children's age.

To test the correlative relationship of child's age with changes in the antibody (lgG) levels, Pearson correlation analysis in conjunction with linear regression was performed. The IgG levels of healthy children, presented in Fig. 3, were used in the analysis. The dark solid line in each figure shows the regression line obtained by the best-fitting to the data sets. The dashed lines represent the $95 \%$ confidence intervals.

HtrAs are implicated in many diseases, including inflammatory disorders (Skorko-Glonek et al., 2013). We found statistically significant differences in the anti-HtrA1, -HtrA3 and -HtrA4 serum IgG levels between the CM patients and healthy controls (Fig. 2), which suggested involvement of the HtrA1, HtrA3 and HtrA4 proteins in pediatric CM. However, since the median age of the control group was higher when compared to the CM children, we performed an additional study which revealed that the anti-HtrA1/3/4 responses increase with age (Fig. 4 and 5). Thus, the results showing that the anti-HtrA1/3 IgG levels are increased in the CM patients are valid or even underestimated. On the other hand, the observed decrease in the anti-HtrA4 response in CM (Fig. 2E) could, at least partially, be caused by the age difference between the $\mathrm{CM}$ and the control group. Increase of the anti- HtrA4 response with age was statistically less significant than that of the anti-HtrA1/3 (Fig. 5), so the error caused by the age difference between the studied groups might not be important. Nevertheless, to be on a safe side, we conclude that taken together, our results suggest involvement of the HtrA1 and HtrA3 proteins in pediatric CM; the involvement of the HtrA4 protein is possible but needs to be investigated further. Unfortunately, it was not possible to repeat all the assays using a better age-matched control sera due to the scarcity of the material obtained from children, especially the youngest ones.
Recently, it has been demonstrated that the HtrA1, -3 and -4 proteins can be transported outside the cell, while the HtrA2 is retained in the cell, mainly in mitochondria (Skorko-Glonek et al., 2013). Thus, the observed differences in the anti-HtrA1, -HtrA3 and -HtrA4 responses may reflect differences in the concentration of the respective antigens in the extracellular space (ECM) due to accumulation of MCs. The observed increased levels of the anti- HtrA1 and anti-HtrA3 antibodies in the group of children with $\mathrm{CM}$ may be associated with an increased concentration of the HtrA1/3 proteins in the ECM of the skin tissue and their interaction with the cutaneous immune system. This assumption is in agreement with the report showing that HtrA1 is highly upregulated during in vitro differentiation of murine mucosal MCs and that the human MCs derived from the cord blood release HtrA1 constitutively, independently of degranulation (Gilicze et al., 2007). Conversely, a decrease in the anti-HtrA4 response in the CM sera could be caused by the interaction of the secreted HtrA1 and HtrA3 proteases with the HtrA4 protein in the ECM. Additionally, it has been shown that HtrA1 and HtrA3 interact with HtrA4 and degrade it (Singh et al., 2011; Chen et al., 2014). The changes in the HtrA proteins' concentrations are probably restricted to the areas where the MCs accumulate, since there were no significant changes in the serum levels of the HtrA $1 / 3 / 4$ proteins between the $\mathrm{CM}$ and control groups (Fig. $3 \mathrm{~A})$. 
The anti-HtrA autoantibodies, when transported to the tissues, including the skin, would form immune complexes with their target antigens, which in turn might stimulate the inflammatory response. One of the possible mechanisms could be stimulation of the MCs, neutrophils and endothelial cells by proteolytic complement fragments generated as the effect of complement activation by the immune complexes. The C3a and $\mathrm{C} 5 \mathrm{a}$ anaphylatoxins are potent mediators of mast cell degranulation, while in neutrophils C5a stimulates motility, adhesion to endothelial cells, and, at high doses, causes stimulation of the respiratory burst and production of reactive oxygen species. In addition, C5a may act directly at vascular endothelial cells and induce increased vascular permeability. There is also a possibility of stimulating the MCs by the anti-HtrA IgG via the Fcy receptors (Metcalfe \& Mecori 2017).

It has been documented that TGF $\beta 1$ suppresses MC development, function and survival, by homeostatic feedback regulation. The TGF $\beta 1$ suppressive activities include decreased proliferation, FceRI and KIT receptor expression and cytokine production (Ryan et al., 2007; Pullen et al., 2012). On the other hand, it has been shown that the HtrA1 and -3 proteases are involved in regulation of the TGF- $\beta$-mediated signal transduction and generally act as inhibitors of this pathway, by modulating levels of several proteins of the TGF- $\beta$ signaling, such as TGF $\beta 1$ protein and TGF- $\beta$ receptors (Fernando et al., 2013). Thus, the HtrA1 and -3 proteases might participate in modulation of the MC proliferation and function via inhibition of the TGF- $\beta$ signaling. It is tempting to speculate that the increased levels of the HtrA1/3 proteases in the skin tissues, due to MC accumulation, might promote $\mathrm{MC}$ proliferation and induction in children with CM. Contrary to this hypothesis is a finding that in the case of murine mucosal MCs, HtrA1 had no inhibitory effect on TGF $\beta 1$-induced differentiation (Gilicze et al., 2007). However, another study showed that the effects of TGF $\beta 1$ on murine MC function in vivo depended upon genetic context. Furthermore, in primary human skin MCs, responsiveness to TGF 1 was also variable (Zurawa-Janicka et al., 2017). Thus, the effect of the HtrA proteins on MCs may also depend on the genotype.

The HtrA1 and -3 proteins may also function as positive regulators of apoptosis. In the case of HtrA1, the best known mechanism of its pro-apoptotic action is degradation of the Inhibitor of Apoptosis Proteins (IAPs) (Chaganti et al., 2015; He et al., 2012). A similar mechanism may apply to HtrA3, since it is able to degrade XIAP, a member of the IAP family (Wenta et al., 2013). However, these events are mediated by the intracellular HtrA1/3 proteins, and have been shown to occur in cultured cancer cells upon stimulation with chemotherapeutic drugs (He et al., 2012; Belford et al., 2010). It is possible that in the case of CM patients' $\mathrm{MCs}$, the proposed pro-proliferative influence of the secreted HtrA1/3 is more important when compared to their intracellular pro-apoptotic activity.

The observed relation between the $\mathrm{CM}$ and the antiHtrA autoantibodies' levels suggests a link between CM and the autoimmune response. This is in agreement with two lines of evidence. Firstly, clinical implication of MCs in inflammatory autoimmune diseases, such as rheumatoid arthritis (RA) and spondyloarthritis (SpA), has been established in several studies (Latar et al., 2016). Secondly, there is a connection between the HtrA1 protease and development of RA and SpA - in patients with these pathologies the HtrA1 gene expression and the level of
HtrA1 protein were significantly elevated, and HtrA1 stimulated fibroblasts' metalloproteinases in articular mucosa (Tiaden et al., 2013). A study of the mice model of arthritis also showed the increase in HtrA1 expression (Hou et al., 2013). Furthermore, HtrA1 is implicated in Age-related macular degeneration (AMD) (Horie-Inou \& Inou, 2014; Tosi et al., 2017) and it is now widely accepted that inflammation and the immune system plays important roles in AMD pathogenesis (Iannaccone et al., 2015).

We do not know yet whether the autoantibodies detected in our study have either partially causal and/ or contributory roles in CM pathogenesis via the above discussed potential mechanisms, and/or which of them may be preeminent. Further studies are required to solve the mechanism of the anti-HtrA response in pediatric $\mathrm{CM}$ and to evaluate its possible application as a diagnostic marker.

\section{Acknowlegments}

We are grateful to our graduate students, B. Gniadkowska and I. Szewczuwianiec for their excellent technical assistance, and to Dr. S. Baranska (University of Gdansk) for her statistical advice.

\section{Acknowlegments of Financial Support}

This work was supported by the National Science Centre (grant no UMO 2016/21/N/N23/03263 to TW) and by University of Gdańsk (grant no: DS 530-L136-D241-17).

\section{REFERENCES}

Belford D, Rattan R, Chien J, Shridhar V (2010) High temperature requirement $\mathrm{A} 3(\mathrm{H} t \mathrm{tA} 3)$ promotes etoposide- and cisplatin-induced cytotoxicity in lungcancer cell lines. J Biol Chem 285: 12011-12027. doi: 10.1074/jbc.M109.097790

Chaganti, LK, Singh N, Bose K (2015) Cathepsins and HtrAs and multitasking proteases in programmed cell death In Proteases Apoptosis Pathw Protoc Transl Adv, Bose K ed, pp 95-141. Springer Internetional Publishing

Chen YY, Chuang PY, Chen CP, Chiu YH, Lo HF, Cheong ML, Huang JY, Kuo PL, Chen H (2014) Functional antagonism between high temperature requirement protein A (HtrA) family members regulates trophoblast invasion. J Biol Chem 289: 22958-22968. doi: 10.1074/jbc.M114.576744

Chien J, Campioni M, Shridhar V, Baldi A (2009) HtrA serine proteases as potential therapeutic targets in cancer. Curr Cancer Drug Targets 9: $451-468$

Clausen T, Kaiser M, Huber R, Ehrmann M (2011) HTRA proteases: regulated proteolysis in protein quality control. Nat Rev Mol Cell Biol 12: 152-162. doi: $10.1038 / \mathrm{nrm} 3065$.

Da Silva E, Jamur M, Oliver C (2014) Mast cell function : a new vision of an old cell. J Histochem Cytochem 62: 698-738. doi: $10.1369 / 0022155414545334$

Fernando J, Faber TW, Pullen NA, Falanga NA, Kolawole EM, Oskeritzian CA, Barnstein BO, Bandara G, Schwartz LB, Spiegel S, Straus DB, Conrad DH, Bunting KD, Ryan JJ (2013) Genotype-dependent effects of TGF- $\beta 1$ on mast cell function: targeting the Stat5 pathway. I Immunol 191: 4505-4513. doi: 10.4049/jimmunol.1202723

Gilicze A, Kohalmi B, Pocza P, Keszei M, Jaeger J, Gorbe E, Papp Z, Toth S, Falus A, Wiener Z (2007) HtrA1 is a novel mast cell serine protease of mice and men. Mol Immunol 44: 2961-2968. https://doi. org/10.1016/j.molimm.2007.01.004

Hansen G, Hilgenfeld R (2013) Architecture and regulation of HtrA family proteins involved in protein quality control and stress response. Cell Mol Life Sci 70: 761-775. doi: 10.1007/s00018-0121076-4

Harlow E, Lane D (1988) Antibodies. A laboratory manual, CSH, Cold Spring Harbor, New York.

He X, Khurana A, Maguire JL, Chien J, Shridhar V (2012) HtrA1 sensitizes ovarian cancer cells to cisplatin-induced cytotoxicity by targeting XIAP for degradation. Int J Cancer 130: 1029-1035. doi: $10.1002 /$ ijc. 26044 
Heinze A, Kuemmet T, Chiu Y, Galbraith S (2017) Longitudinal study of pediatric urticarial pigmentosa. Pediatr Dermatol 34: 144-149. doi: $10.1111 /$ pde. 13066

Horie-Inoue K, Inoue S (2014) Genomic aspects of age-related macular degeneration. Biochem Biophys Res Commun 452: 263-275. doi: 10.1016/j.bbrc.2014.08.013

Hou Y, Lin H, Zhu L, Liu Z, Hu F, Shi J, Yang T, Shi X, Zhu M, Godley BF, Wang Q, Li Z, Zhao Y (2013) Lipopolysaccharide increases the incidence of collagen-induced arthritis in mice through induction of protease HTRA-1 expression. Arthritis Rheum 65: 2835-2846. doi: 10.1002/art.38124.

Iannaccone A, Giorgianni F, New D, Hollingsworth TJ, Umfress A, Alhatem AH, Neeli I, Lenchik NI, Jennings BJ, Calzada JI, Satterfield S, Mathews D, Diaz RI, Harris T, Johnson KC, Charles S, Kritchevsky SB, Gerling IC, Beranova-Giorgianni S, Radic MZ (2015) Health ABC study. Circulating autoantibodies in age-related macular degeneration recognize human macular tissue antigens implicated in autophagy, immunomodulation, and protection from oxidative stress and apoptosis. PLoS One 10: e0145323. doi: 10.1371/ journal.pone. 0145323

Laemmli UK (1970) Cleavage of the structural protein during assembly of the head of bacteriophage T4. Nature 227: 680-685

Lange M, Niedoszytko M, Renke J, Gleń J, Nedoszytko B (2013) Clinical aspects of paediatric mastocytosis: a review of 101 cases. JEADV 27: 97-102. doi: 10.1111/j.1468-3083.2011

Latar I, Koufany M, Hablot J, Loeuille D, Netter P, Jouzeau JY, Chary-Valckenaere I, Moulin D (2016) Association between rheumatoid arthritis and systemic mastocytosis: a case report and literature review. Clin Rheumatol 35: 2619-2623. doi: 10.1007/s10067-0163368-9

Lipinska B, Zylicz M, Georgopoulos C (1990) The HtrA (DegP) protein, essential for Escherichia coli survival at high temperatures, is an endopeptidase. J Bacteriol 172: 1791-1797

Melcalfe D, Mecori Y (2017) Pathogenesis and pathology of mastocytosis. Annu Rev Pathol 12: 487-514. doi: 10.1146/annurev-pathol-052016-100312

Narkiewicz J, Klasa-Mazurkiewicz D, Zurawa-Janicka D, SkorkoGlonek J, Emerich J, Lipinska B (2008) Changes in mRNA and protein levels of human HtrA1, HtrA2 and HtrA3 in ovarian cancer. Clin Biochem 41: 561-569. doi: 10.1016/j.clinbiochem.2008.01.004

Pullen NA, Falanga YT, Morales JK, Ryan JJ (2012) The Fyn-STAT5 Pathway: A New Frontier in IgE- and IgG-Mediated Mast Cell Signaling. Front Immunol 3: 117. doi: 10.3389/fimmu.2012.00117.

Ryan JJ, Kashyap M, Bailey D, Kennedy S, Speiran K, Brenzovich J, Barnstein B, Oskeritzian C, Gomez G (2007) Mast cell homeostasis: a fundamental aspect of allergic disease. Crit Rev Immunol 27: 15-32

Singh N, Kuppili R, Bose K (2011) The structural basis of mode of activation and functional diversity: a case study with HtrA family serine proteases. Arch Biochem Biophys 516: 85-96. doi: 10.1016/j. abb.2011.10.007

Skorko-Glonek J, Zurawa-Janicka D, Koper T, Figaj D, Glaza P, Lipinska B (2013) HtrA protease family as therapeutic targets. Curr Pharm Des 19: 977-1009

Tiaden A, Richards P (2013) The emerging roles of HtrA1 in musculoskeletal disease. Am J Pathol 182: 1482-1488. doi: 10.1016/j.ajpath.2013.02.003

Tosi G, Caldi E, Neri G, Nuti E, Marigliani D, Baiocchi S, Traversi C, Cevenini G, Tarantello A, Fusco F, Nardi F, Orlandini M, Galvagni F (2017) HtrA1 and TGF- $\beta 1$ concentrations in the aqueous humor of patients with neovascular age-related macular degeneration. Invest Ophthalmol Vis Sci 58: 162-167. doi: 10.1167/iovs.16-20922.

Wenta T, Glaza P, Jarząb M, Zarzecka U, Zurawa-Janicka D, Lesner A, Skorko-Glonek J, Lipinska B (2017) The role of the LB structural loop and its interactions with the PDZ domain of the human HtrA3 protease. Biochim Biophys Acta 1865: 1141-1151. doi: 10.1016/j.bbapap.2017.06.013

Zhao J, Zhang X, Zhang M, Feng J Qu (2016) High temperature requirement A3 (HtrA3) expression predicts postoperative recurrence and survival in patients with non-small-cell lung cancer. Oncotarget 7: 40725-40734. doi: 10.18632/oncotarget.9173

Zurawa-Janicka D, Wenta T, Jarzab M, Skorko-Glonek J, Glaza P, Gieldon A, Ciarkowski J, Lipinska B (2017) Structural insights into the activation mechanisms of human HtrA serine proteases. Arch Biochem Biophys 621: 6-23. doi: 10.1016/j.abb.2017.04.004 